\title{
Badanie osi drążonych w zestawach pociągów
}

\section{The examination of hollow axles in sets of trains}

\section{Streszczenie}

Badanie osi drążonych w zestawach pociągów. Brak obecności odpowiednich norm regulujących ultradźwiękowe badania kolejowych zestawów kołowych jak również badań osi drążonych powoduje konieczność podjęcia działań kierujących ku poprawie bezpieczeństwa eksploatacji wymienionych elementów. Bezpieczeństwo eksploatacji osi kolejowych związane jest z wykryciem nieciągłości materiałowych jakimi są m.in. pęknięcia jak w najwcześniejszym etapie ich powstawania. Istotną zaletą badania osi drążonych jest wykonanie badania bez konieczności demontażu zestawów kołowych i przeprowadzenie badania $w$ dowolnym miejscu po demontażu pokrywy maźnic. Bardzo dużą zaletą jest również zwiększenie szybkości wykonywania badań.

Słowa kluczowe: osie drążone, badania ultradźwiękowe UT, personel NDT

\section{Abstract}

The examination of hollow axles in sets of trains. The lack of appropriate standards regulating the ultrasonic testing of railway wheel sets as well as the examination of hollow axles makes it necessary to take action towards improving the safety and reliability of these elements. The operational safety of rail axes is associated with detection of material voids that include, among others, cracks in the earliest stage of their formation. An important advantage of the hollow axle test is making it without dismantling the wheelsets and performing it in any place after removing the cover of the axle boxes. A major advantage is also an increase in speed of making the tests.

Keywords: hollow axles, ultrasonic testing UT, NDT personnel

\section{Wstęp}

Początki badań w Polsce sięgają lat 60 ubiegłego wieku. Wtedy to staraniami Instytutu Kolejnictwa opracowano procedury badania osi z powierzchni czołowych i powierzchni bocznych.

W dzisiejszych czasach brak obecności odpowiednich norm regulujących ultradźwiękowe badania kolejowych zestawów kołowych jak również badań osi drążonych powoduje konieczność podjęcia działań kierujących ku poprawie bezpieczeństwa eksploatacji wymienionych elementów. Bezpieczeństwo eksploatacji osi kolejowych związane jest z wykryciem nieciągłości materiałowych jakimi są m.in. pęknięcia jak w najwcześniejszym etapie ich powstawania [2] [3].

Osie drążone były jednym z elementów obniżających awaryjność kolejowych zestawów kołowych. Otwór drążony wzdłuż osi pozwala na badanie ultradźwiękowe wewnątrz osi z powierzchni otworu drążonego bez jednoczesnego obniżenia ich wytrzymałości. Istotną zaletą badania osi drążonych jest wykonanie badania bez konieczności demontażu zestawów kołowych i przeprowadzenie badania w dowolnym miejscu po demontażu pokrywy maźnic. Bardzo dużą zaletą jest również zwiększenie szybkości wykonywania badań. [1]

$\mathrm{Na}$ rysunku 1 przedstawiony jest widok kompletnego zestawu kołowego oraz po usunięciu maźnic kół z przygotowaniem do badania ultradźwiękowego osi drążonych.
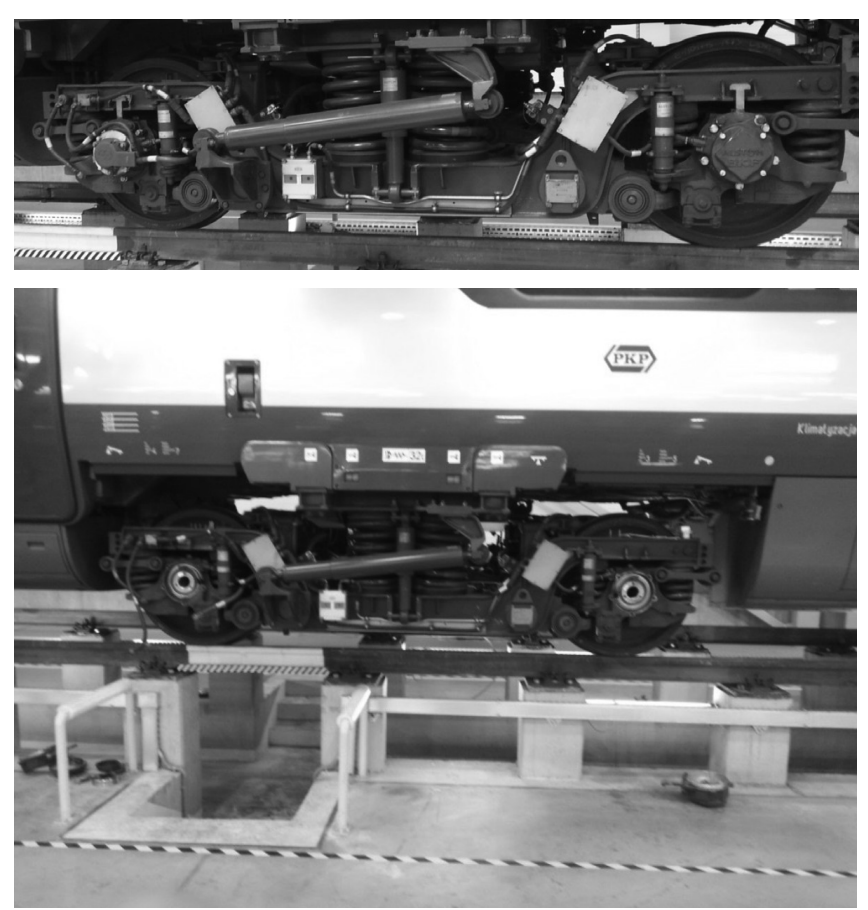

Rys. 1. Widok zestawu kołowego pociągu w stanie zmontowanym oraz po zdjęciu maźnic kół

Fig. 1. A view of train wheelset in an assembled state and after removing axle boxes of the wheels

Mgr inż. Łukasz Rawicki - Instytut Spawalnictwa.

Autor korespondencyjny/Corresponding author. lukasz.rawicki@is.gliwice.pl 
Czołowa część osi drążonej zawiera oznakowanie podające m.in numery wytopu, zestawu kołowego, osi badanej co pokazane jest na rysunku 2.

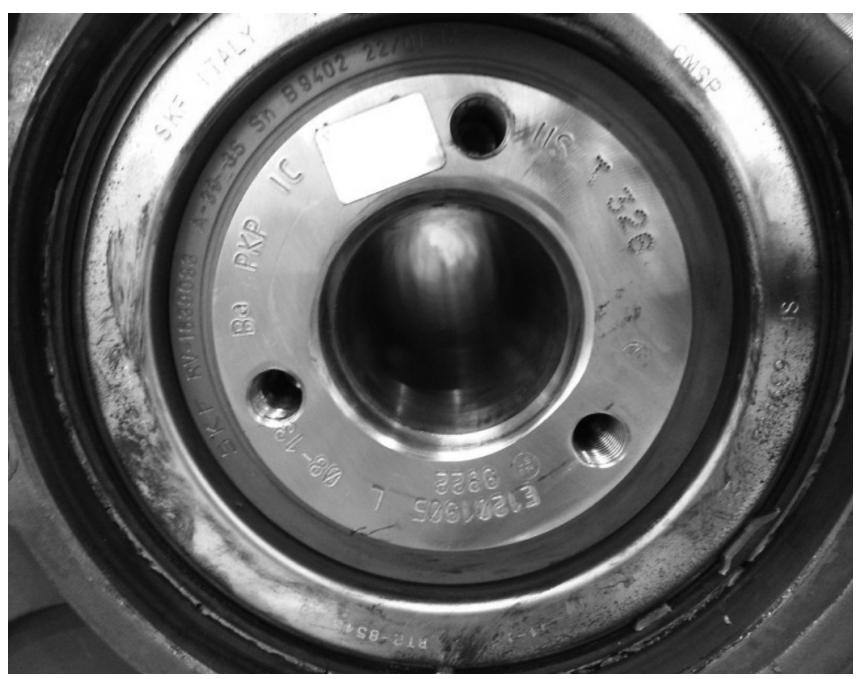

Rys. 2. Widok osi drążonej z pozycji czołowej po zdjęciu maźnic kół Fig. 2. A view of a hollow axle from the front position after removing axle boxes of the wheels

\section{Przebieg badania}

Personel wykonujący badanie winien posiadać uprawnienia certyfikatów kompetencji minimum 2 stopnia w metodzie badań ultradźwiękowych UT w sektorze Utrzymanie Ruchu Kolei zgodnie z PN EN ISO 9712.

Wczasiewykonywaniabadania ośzestawukołowego winna być umieszczona w bezpiecznym położeniu umożliwiającym
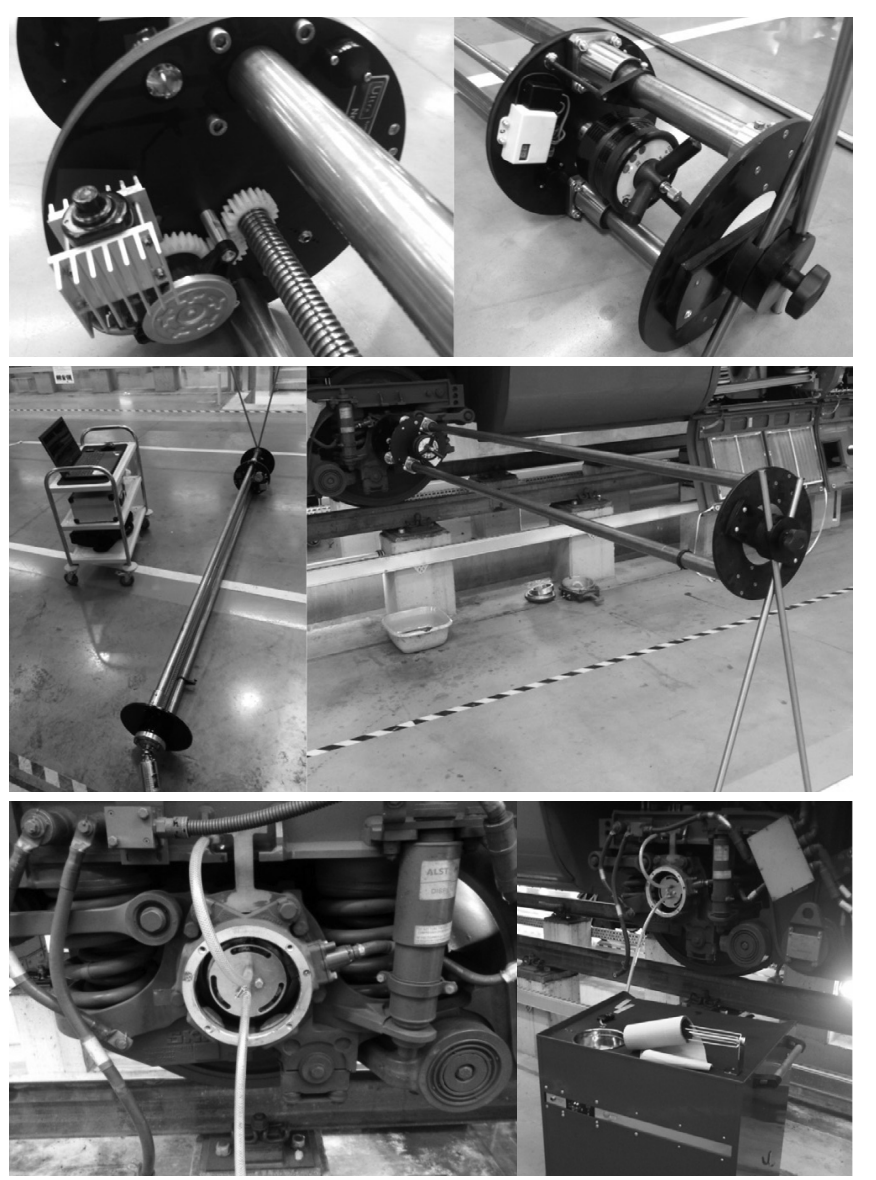

Rys. 3. Widok aparatury badawczej wraz z widokiem montażu urządzenia do dopływu oleju

Fig. 3. A view of test equipment and assembling of the equipment for the oil supply swobodne wykonanie badania, a aparatura badawcza nie może być wystawiona na żadne wpływy uszkodzenia mechanicznego co w konsekwencji może powodować uszkodzenie sprzętu. [1]

Wykorzystana aparatura badawcza do badania osi drążonych pokazana na rysunku 3, zawiera m.in. bezprzewodowy defektoskop ultradźwiękowy łączący się przez sieć WIFI z komputerem typu laptop do rejestracji i zapisów badania, część konstrukcyjna urządzenia ze śrubą posuwową na końcu której zamontowana jest sonda badawcza. Zestaw do badania zawiera również urządzenie do podawania oleju w celu zapewnienia sprzężenia akustycznego głowicy w trakcie badania.

Przy badaniach ultradźwiękowych osi kolejowych czynnikami które mają duże znaczenie podczas wykonywania badania są m.in. układ geometryczny badania na który wpływ ma miejsce i kąt przyłożenia głowic oraz weryfikacja wyników badania na wzorcu porównawczym. Każdy typ osi różni się względem siebie kształtem więc wzorzec musi być dopasowany właściwie do przeprowadzonego badania. Prawidłowe szkolenia personelu badań nieniszczących, kontrola i ich certyfikacja. [1,2]

Badanie porównawcze z wzorcem osi eksploatowanej ma wiele zalet m.in. duża prostota i wiarygodność badania co wpłynęło na zmniejszenie liczby awaryjności zestawów kołowych. Wykonanie badania winno być poprzedzone kalibracją sprzętu pomiarowego na certyfikowanym wzorcu odpowiadającym danej osi badanej z uwzględnieniem danej procedury i normy. Wzorzec powinien być zawsze dostępny dla operatora. Na osi wzorcowej pokazanej na rysunku 4 wykonane są nacięcia o głębokości $2 \mathrm{~mm}$. Przeprowadzenie kalibracji sprzętu pomiarowego nie powinno być przeprowadzone na innych osiach które są stosowane jako zamienniki badawcze danej osi. [2]

Kalibracja sprzętu pomiarowego polega na wykreśleniu krzywej DAC na wzorcu pomiarowym. W tym celu układ z sondom badawczą wprowadza się do badanej osi i w posuwistym

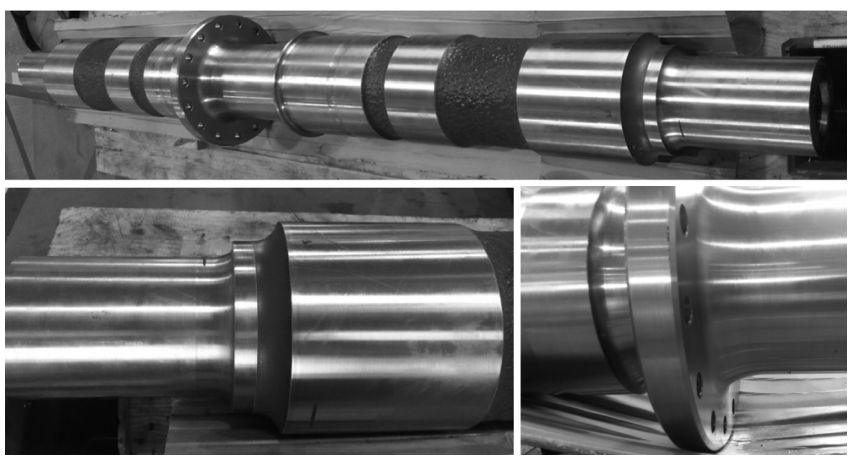

Rys. 4. Nacięcia kalibracyjne na wzorcu porównawczym wraz z wymiarami

Fig. 4. Calibration cuts on the benchmark with dimensions

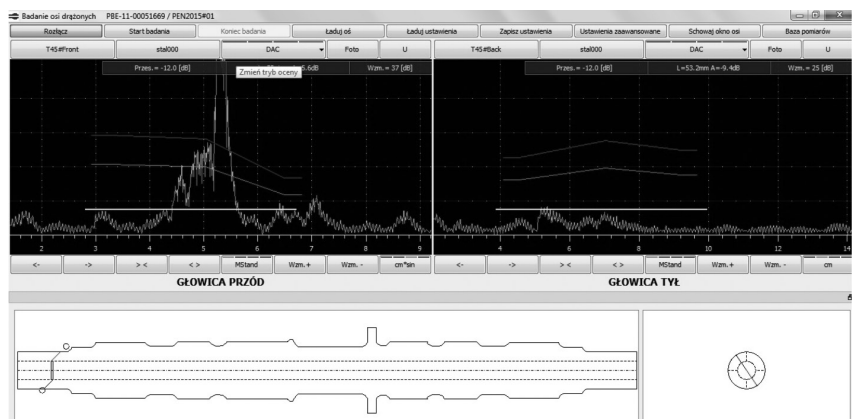

Rys. 5. Widok krzywych DAC podczas badania osi napędowej dla głowicy przedniej i tylnej

Fig. 5. A view of DAC curves during testing of a drive axle for front and rear head 
ruchu sondy wyszukuje się kolejnych nacięć znajdujących się na wzorcu kontrolo-pomiarowym osi. Nacięcia będące wadami sztucznymi służą do wyznaczenia krzywej DAC. Tworzenie krzywej DAC polega na znalezieniu ech maksymalnych które pochodzą od kolejnych nacięć znajdujących się na wzorcu kontrolo-pomiarowym. Linia poprowadzona przez poszczególne punkty ech maksymalnych wyznacza krzywą DAC. Wykreśloną krzywą należy obniżyć o 12dB w celu zaostrzenia kryterium badania. [1]

$\mathrm{Na}$ rysunku 5 pokazane są krzywe DAC wykreślone do przeprowadzenia badania osi napędowej. Program umożliwia tworzenie krzywych DAC dla głowicy przedniej i tylnej.

Podczas badania osi drążonych, głowice poprzez układ sprężyn dociskane są do części wewnętrznej powierzchni otworu. W celu dobrego sprzężenia akustycznego głowicy z powierzchnią wewnętrzną otworu stosuje się olej hydrauliczy. Brak sprzężenia może być powodem błędnego odczytu wskazań podczas przeprowadzania badania lub nie odczytywanie niektórych przejść na osiach podczas przesuwu głowicy w trakcie badania. Dwie głowice badawCze $2 \mathrm{~T} 45^{\circ} 15 \times 15$ jedna do przodu druga do tył umieszczone są pod kątem $45^{\circ}$ co pokazane jest na rysunku 6 .

Operator wykonujący badanie musi rózróżnić echa pocho-

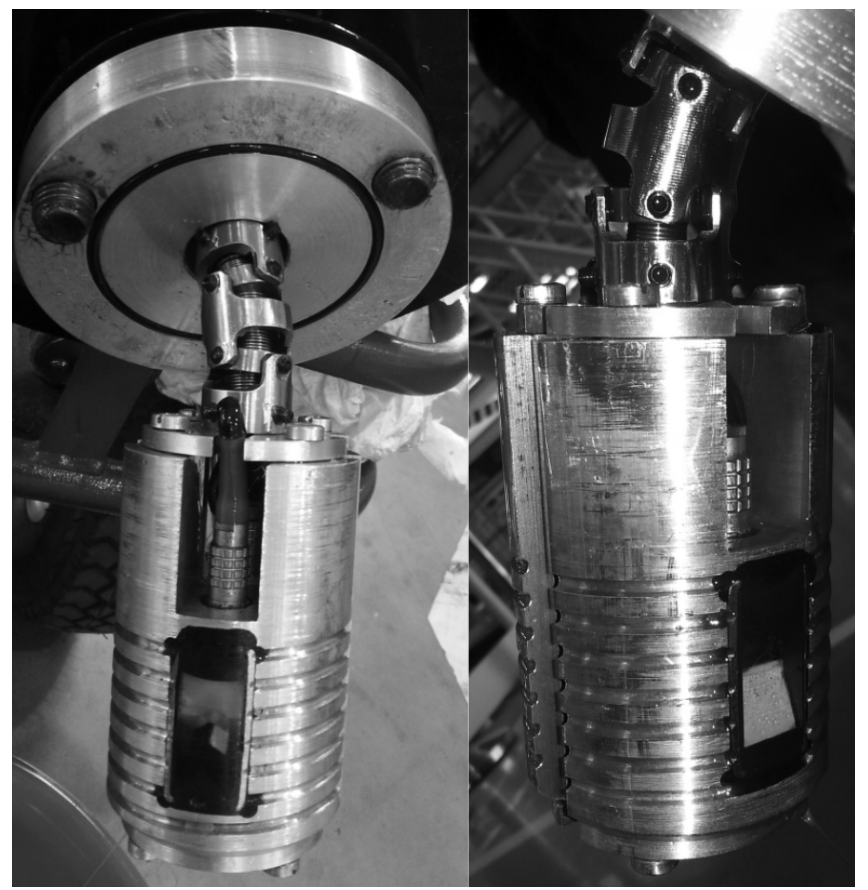

Rys. 6. Widok głowic przedniej i tylnej sondy badawczej

Fig. 6. A view of a front and rear head of a testing probe dzące od wad stanowiących wskazania prawdziwe a pominąć i nie brać pod uwagę wskazań fałszywych. Wskazania interpretowane są na podstawie identyfikacji głowicy na której stwierdzono wskazanie, a następnie podawane ocenie czy spełniają wartości akceptowalne zgodnie z krzywą DAC. Wskazania istotne od nieciągłości materiałowych należy zarejestrować. Omijane są wskazania od nieciągłości pozornych wynikających m.in. z geometrii osi, transformacji fali, przejściem fali na przestrzeni podpiaście-koło i czop-łożysko. Wskazania fałszywe należy rozpatrzyć biorąc pod uwagę odległość na jakiej nastąpiło wskazanie, oraz analizę czy wskazanie ma charakter ciągły i występuje na całym obwodzie. Miejsca od wskazań problematycznych należy ponownie rozpatrzyć przez przeprowadzenie badania ponownie. [1]

W czasie badania operator winien się upewnić, że układ wrócił do punktu startowego w którym rozpoczyna się badanie. Pomiar głębokości na której znajdują się głowice dokonywany jest automatycznie przez program na podstawie zliczanych obrotów. Operator urządzenia ultradźwiękowego w czasie badania ma do dyspozycji informacje w postaci długości promienia ultradźwiękowego od głowicy do nieciągłości i lokalizacji nieciągłości w postaci parametru jakim jest odległość od czoła osi.

Badanie przeprowadzane jest na całej długości osi a nieciągłości zostają rejestrowane automatycznie przez program.

Końcowe wyniki badania pokazane na rysunku 7 przedstawiają zapis badania niezaleznie dla głowicy przedniej i tylnej jak również identyfikację przejść na osi tocznej. Zadaniemoperatorajestoceanawskazańna osiachbadanych i weryfikacja wyników badania. Operator powinien określić i ocenić wskazania istotne a pominąć wskazania które mogą być wynikiem m.in echa kszatttu.

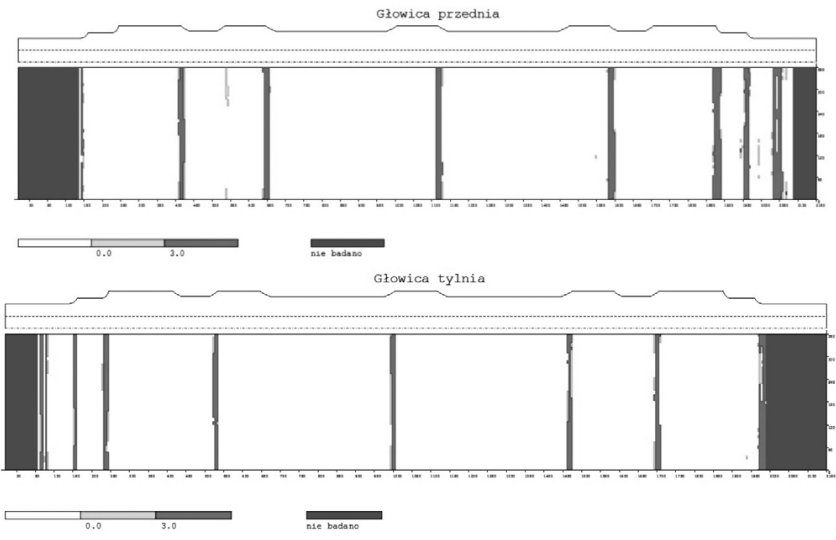

Rys. 7. Końcowe wyniki badań z głowicy przedniej i tylnej dla osi tocznej Fig. 7. Final testing results of the front and rear head for a rolling axle

\section{Podsumowanie}

W przedstawionym opracowaniu pokazano sposób badania osi drążonych w pociągach szybkobieżnych. Brak literatury oraz norm powoduje konieczność podjęcia tematu i zainteresowania się przedstawioną tematyką badania.

Sposób badania jest badaniem automatycznym umożliwiającym m.in. kontrolę i rejestrację przez program komputerowy wyników badania. Operator posiadający stosowne uprawnienia w sektorze Utrzymanie Ruchu Kolei odpowiada za ocenę i interpretację wyników badania.

\section{Literatura}

[1] Procedura badania ultradźwiękowego osi kolejowych zestawów koło wych- Zakład Badań Materiałów ULTRA

[2] DIN 27201-7 Stan pojazdów kolejowych - podstawy i technologie wykonania. Część 7: badania nieniszczące.
[3] PN-EN 15313:2010 Kolejnictwo- Wymagania eksploatacyjne dotyczące obsługi zestawów kołowych- Utrzymanie zestawów kołowych pojazdów w eksploatacji i wyłączonych z eksploatacji. 